\title{
Intersensory integration and reading ability in the deaf*
}

\author{
DORIS V. ALLEN \\ Center for Health Research \\ Wayne State University, Detroit, Mich. 48202 \\ and \\ RALLE K. ROTHMAN \\ Detroit Board of Education, Detroit, Mich. 48202
}

Other research has suggested that auditory-visual integration is a correlate of reading ability. This relationship was examined in congenitally deaf children identified as good and poor readers. Auditory-visual integration failed to discriminate between the two reading categories, but tactile-visual integrative performance did reflect reading ability differences.

The relationship between auditory-visual (A-V) integration, or crossmodal perception, and reading has been explored by many investigators. Butters \& Brody (1968) studied adults with cortical damage and found impaired reading skills to be correlated with poor A-V performance. Geschwind (1964), reviewing both animal and human studies, theorized that language skills are dependent upon the ability to form crossmodal associations, "particularly visual-auditory and tactile-auditory [p. 163]." Studies with younger Ss reinforce this conclusion. Birch \& Belmont $(1964,1965)$ and others (Ford, 1967; Rudnick, Sterritt, \& Flax, 1967) showed that A-V integration is especially important for reading ability in the lower grades, while Muehl \& Kremenak (1966) found both A-V and visual-auditory performance to be significant predictors of reading in the first grade.

Sterritt \& Rudnick (1966) studied both A-V and visual-visual (V.V) performance in fourth graders, where V.V involved the "ability to transpose from temporal to spatial formats within the visual modality." They found V-V performance was not related to reading but that A-V was, consistent with other studies. They offered two explanations for the obtained relationship, both supported by other research. One explanation was based upon difficulties in shifting between modalities among poor readers, while the other explanation suggested that poor auditory memory may be the underlying basis for the obtained relationship. However, Sterritt and Rudnick failed to note that Birch \& Belmont (1964) had already discounted auditory short-term memory as a factor in the relationship between $\mathrm{A} \cdot \mathrm{V}$ performance and

*This study was submitted by $\mathrm{R}$ alle $\mathrm{K}$. Rothman in partial fulfillment of the requirements for the degree of Master of Arts, Department of Speech (Audiology), Wayne State University, 1971. reading ability. In a later study, Ford (1967) also ruled out auditory memory.

Rudnick et al (1967) had pointed to the reading deficiencies of the deaf as further evidence for the relationship between auditory-visual integration and reading ability, but this had not been formally investigated. The present study was undertaken specifically to examine these variables in the deaf. It has usually been assumed that the reading deficiencies of the deaf are attributable to the lack of a prior oral language. The child with normal hearing learns to read by establishing crossmodal equivalencies between the printed word and the familiar oral word. Since this is not the case in the deaf, perhaps auditory-visual integration may not be the appropriate intersensory skill related to reading ability in this population. Even for hearing Ss there is some confusion regarding the relationship between tactile-visual integrative skills and reading, with some (e.g., Buchner, as cited by Ford, 1967) reporting positive findings and others (Butters \& Brody, 1968; Ford, 1967) finding no relationship between the two. Geschwind (1964) had suggested that tactile-visual associations might be important in language acquisition by the deaf. Furthermore, the tactile sense is closely related to audition (Handel \& Buffardi, 1968), and the deaf have demonstrated superior tactile discrimination (Blank \& Bridger, 1966; Rosenstein, 1957). For these reasons, it seemed appropriate to examine this modality with respect to reading ability in the deaf.

This study, then, was designed to test the hypothesis that auditory-visual integration is significantly related to reading ability in the deaf, as in hearing Ss, and also to explore the relationship between tactile-visual integration and reading ability. Mindful of the charges made by Bryant (1968) that intramodal performance should be assessed before attempting to interpret intermodal performance, intramodal tasks in the three modalities were also included for study.

\section{METHOD \\ Subjects}

A total of 20 Ss participated in this study; all were enrolled in a private residential school for the deaf. Discussion with administrators of the school indicated that available reading scores were known to be unreliable for several reasons; therefore, it was decided to use teachers' evaluations of the reading proficiency of the children to define two groups, one with relatively good reading skills and the other exhibiting reading difficulties. Thus, the school was requested to identify 10 good readers and 10 poor readers from essentially equivalent grades or classes prior to the initiation of the study. Teachers were not aware of the purpose for the classifications.

As other studies have shown, a sex difference in reading ability was apparent in these groups; the 10 good readers 
Table 1

Summary of Performance of Each Group on Five Tasks

\begin{tabular}{|c|c|c|c|c|c|c|}
\hline \multirow[b]{2}{*}{ Group } & \multirow[b]{2}{*}{ Item } & \multicolumn{3}{|c|}{ Intramodal Tasks* } & \multicolumn{2}{|c|}{ Intermodal Tasks** } \\
\hline & & $\mathrm{V}-\mathrm{V}$ & T-T & A-A & $A \cdot V$ & $\mathrm{~T}-\mathrm{V}$ \\
\hline $\begin{array}{l}\text { Good Readers } \\
(\mathrm{N}=10)\end{array}$ & $\begin{array}{l}\text { Mean } \\
\text { s } \\
\text { Range } \\
2 \mathrm{M}^{\dagger}\end{array}$ & $\begin{array}{r}16.8 \\
2.4 \\
12-20 \\
17,19\end{array}$ & $\begin{array}{r}15.6 \\
3.8 \\
8-20 \\
14,19\end{array}$ & $\begin{array}{r}13.9 \\
2.2 \\
10-19 \\
13,15\end{array}$ & $\begin{array}{r}11.9 \\
4.2 \\
5-19 \\
5,14\end{array}$ & $\begin{array}{r}15.5 \\
3.2 \\
10-19 \\
13,16\end{array}$ \\
\hline $\begin{array}{l}\text { Poor Readers } \\
(N=10)\end{array}$ & $\begin{array}{l}\text { Mean } \\
\text { s } \\
\text { Range } \\
2 \mathrm{~F} \dagger\end{array}$ & $\begin{array}{r}15.2 \\
4.2 \\
7-20 \\
15,19\end{array}$ & $\begin{array}{r}13.9 \\
3.4 \\
9-19 \\
13,15\end{array}$ & $\begin{array}{r}13.3 \\
2.2 \\
10-17 \\
13,14\end{array}$ & $\begin{array}{r}13.2 \\
4.6 \\
5-19 \\
8,17\end{array}$ & $\begin{array}{c}12.5 \\
4.6 \\
5-18 \\
12,13\end{array}$ \\
\hline
\end{tabular}

*In order administered.

**Order counterbalanced in each group.

tScores for the two males among "good readers" and two females among "poor readers."

included eight girls, while the 10 poor readers had eight boys in the group. This was not viewed as introducing bias into the study, since Birch \& Belmont (1965) reported no sex differences in auditory-visual performance. The ages of the two groups were similar (10-15 years with a mean of 12 for good readers and 10-16 years with a mean of 14 for poor readers) and the groups were alike in hearing ability (good readers ranged from 46 to $90 \mathrm{~dB}$ with a mean of 77 and poor readers ranged from 40 to $115 \mathrm{~dB}$ with a mean of 75 , expressed as better ear average for the three speech frequencies, re ISO, 1964, norms).

\section{Apparatus}

Auditory stimuli were delivered by earphones to the better ear. Pure tone signals of 250,500 , or $1000 \mathrm{~Hz}$ were used; the frequency selected was that which was best for each $S$ in that it allowed suprathreshold presentation but was below "cutile" thresholds (Nobler, 1968). Vibratory signals of $250 \mathrm{~Hz}$ at $45 \mathrm{~dB}$ were used as tactile stimuli and were delivered by a bone conduction oscillator, held by the $S$ between the thumb and first two fingers of one hand. Two kinds of visual stimuli were used: One consisted of flashes of a small battery-operated flashlight bulb mounted in a plastic base and covered with an opaque white dome; the other was printed dot patterns on index cards.

All temporal patterning was monitored by the examiner through the use of a metronome with a click signal. The intensity of this click was attenuated well below the auditory thresholds of any of the Ss, and the metronome was placed out of view of all but the E. Stimulus durations were $1 / 2 \mathrm{sec}$, short off times were as brief as possible, longer off times were $1 / 2 \mathrm{sec}$, and a 1-sec interval separated the two patterns of a pair.

\section{Procedure}

Three intramodal tasks involving same-different judgments preceded two intermodal tasks using a multiple-choice response. Intramodal tasks were performed first to provide practice for the more difficult intermodal tasks. All testing was done individually, alternating Ss from each group, and nonverbal instructions were used. Practice trials preceded each task until the $\mathrm{E}$ was confident that the $\mathrm{S}$ understood the directions. The first test item was simple; if the incorrect response was made, additional practice was allowed before the task was again initiated. The score on the first item was not changed, however.

Intramodal tasks were administered in a fixed order of increasing difficulty, with visual-visual (V-V) first and auditory-auditory (A-A) last. Twenty pairs of stimulus patterns were used, taken from Ford (1967); these were the same for all three intramodal tasks. The V-V task consisted of presenting a pattern of flashes for the first stimulus and a printed dot pattern for the second, which was similar to the V-V task used by Sterritt \& Rudnick (1966). Ss judged "same" or "different." For the T-T and A-A tasks, both patterns were presented temporally.
Following completion of the intramodal tasks, Ss received the two intermodal tasks, auditory-visual (A-V) and tactile-visual (T-V), the order being counterbalanced within each group. Again there were 20 items of increasing difficulty, but now a multiple-choice response format was used to conform to other studies. Three printed dot patterns were available to the $S$ after each stimulus presentation, and the $S$ circled the pattern which he thought corresponded to the stimulus pattern. All data are number of correct responses.

\section{RESULTS}

Table 1 summarizes the performance of each group on the five tasks used in this study. Since the two groups differed in sex ratio, the scores of the two males who were good readers and the two females who were poor readers were examined further. Their scores are presented in Table 1, along with the ranges of scores for all Ss in each group. No trends to suggest a sex difference are apparent; intercorrelations of sex with any of the tasks were not significant.

Analysis of variance of the three intramodal tasks showed that modality was the only significant source of variance in these tasks, $\mathrm{F}(2,36)=4.89, \mathrm{p}<.05$; postmortem tests showed that V-V and A-A were significantly different from each other but not from $T-T$. The two groups of readers did not differ, nor did reading ability interact with modality. The A-A task was much more difficult for either group, in spite of the fact that practice was provided by the two preceding tasks, with neither group performing much above what might be obtained by chance.

Analysis of variance of the two intermodal tasks found the interaction between tasks and groups to be the only significant source of variance, $F(1,18)=8.64$, $p<.01$. Postmortem tests showed that the superior performance of the good readers on the T-V task was the source of the interaction. None of the other differences, either between groups or between conditions, was significant.

\section{DISCUSSION}

This study shows that T-V integration is related to reading ability in the deaf, as suggested by Geschwind (1964), rather than $\mathrm{A}-\mathrm{V}$ integration, as had been reported for hearing Ss. It also 
supports the finding of Sterritt \& Rudnick (1966) that V-V integration is not related to reading ability. It should also be noted that the T-V task used here is different from that used by others (Butters \& Brody, 1968; Ford, 1967). Those studies had used form perception as the dimension for the T-V task rather than pattern perception. Therefore, the relationship between $\mathrm{T}-\mathrm{V}$ integration and reading ability in hearing Ss deserves further study.

The failure of $\mathrm{A}-\mathrm{V}$ integration to differentiate between good and poor readers in this study is undoubtedly related to the poor performance of both groups on the A-A task, with neither group being much above chance. What this study does demonstrate is that the deaf can perform intersensory integrative tasks if they can perform adequately on the intramodal tasks and that such intersensory performance is significantly related to reading ability. Milne (1968) had stated that intermodal "transfer should be demonstrable at any age where the child is capable of solving the intramodal tasks." Our data do not support this, since both good and poor readers performed alike on T-T and V-V tasks but differed on $\mathrm{T}-\mathrm{V}$.

Overall, this study helps to choose between the two explanations offered by Sterritt \& Rudnick (1966). Auditory memory does not seem to be an adequate explanation, since again in this study it has failed to discriminate between good and poor readers. Auditory memory is the major factor in performance on the A-A task and good readers failed to show any superiority. These findings instead add support to the first explanation advanced by Sterritt and Rudnick, that the ability to shift from one modality to another may be the critical variable relating crossmodal performance to reading ability.

As Sterritt, Rudnick, \& Martin (1967) have pointed out, it is not yet known whether ability to perform crossmodal tasks precedes or is a result of learning to read. Geschwind (1964, 1970) theorized that the ability to form crossmodal associations is a prerequisite to the ability to acquire language, but this is still a testable hypothesis. Even given that it is supported, the next question might be whether this skill is amenable to training. Again, this is open to experimental verification. The implications for the education of the deaf and of all persons with reading disabilities are great. At present, one can only say that intersensory integration and reading ability are positively related in both hearing and deaf populations but no causality should be inferred. Much research is still to be done before specific recommendations can be made.

\section{REFERENCES}

Birch, H. G., \& Belmont, L. Auditory-visual integration in normal and retarded readers. American Journal of Orthopsychiatry, 1964, 34, 852-861.

Birch, H. G., \& Belmont, L. Auditory-visual integration, intelligence, and reading ability in school children. Perceptual \& Motor Skills, 1965, 20, 295-305.

Blank, M., \& Bridger, W. H. Conceptual cross-modal transfer in deaf and hearing children. Child Development, 1966, 37, 29-38.

Bryant, P. E. Comments on the design of developmental studies of cross-modal matching and cross-modal transfer. Cortex, $1968,4,127-137$.

Butters, N., \& Brody, B. A. The role of the left parietal lobe in the mediation of intra- and cross-modal associations. Cortex, $1968,4,328-343$.

Ford, M. P. Auditory-visual and tactual-visual integration in relation to reading ability. Perceptual \& Motor Skills, 1967, 24, 831-841.

Geschwind, $N$. The development of the brain and the evolution of language. Monograph Series on Languages and Linguistics, 1964, No. 17, 155-169.

Geschwind, N. Intermodal equivalence of stimuli in apes. Science, 1970, 168, 1249

Handel, S., \& Buffardi, L. Pattern perception: Integrating information presented in two modalities. Science, 1968, 162, 1025-1028.

Milne, A. M. Crossmodal relations in vision and touch: A developmental study. Paper presented at meeting of the Eastern Psychological Association, 1968.

Muehl, S., \& Kremenak, S. Ability to match information within and between auditory and visual sense modalities and subsequent reading achievement. Journal of Educational subsequent reading achieveme
Psychology, 1966, 57, 230-239.

Nobler, E. H. Air and bone conduction thresholds of deaf and normal hearing subjects before and during the elimination of cutaneous-tactile interference with anesthesia. Final Report, Project No, 6-3073, Grant OEG-1-063-073-2198. Washington, D.C: Bureau of Research, Office of Education, U.S. Department of Health, Education, \& Welfare, 1968.

Rosenstein, J. Tactile perception of rhythmic patterns by normal, blind, deaf, and aphasic children. American Annals of the Deaf, 1957, 102, 399-403.

Rudnick, M., Sterritt, G. M., \& Flax, M. Auditory and visual rhythm perception and reading ability. Child Development, $1967,38,581-587$.

Sterritt, G. M., \& Rudnick, M. Auditory and visual rhythm perception in relation to reading ability in fourth grade boys. Perceptual \& Motor Skills, 1966, 22, 859-864.

Sterritt, G. M., Rudnick, M., \& Martin, V. E. Research design problems. Paper presented at a symposium entitled "Perceptual development and reading" at the meeting of the Society for Research in Child Development, New York, 1967.

(Received for publication December 13, 1972.) 